\title{
Improving the dynamic performances of an MPPT controller for a Photovoltaic system using fuzzy logic
}

\author{
Hassan Essakhi ${ }^{1 *}$, Sadik Farhat ${ }^{1}$, Mohamed Mediouni ${ }^{1}$, and Yahya Dbaghi $^{1}$ \\ ${ }^{1}$ Department of Electric Engineering, High school of technology - Ibn Zohr University, LASIME Lab, Agadir Morocco 80150
}

\begin{abstract}
This paper deals with analysis, modeling, and simulation of a Photovoltaic (PV) system with an intelligent Maximum Power Point Tracking (MPPT) controller based on fuzzy logic and to compare the dynamic performances: rapidity and stability of a fuzzy controller with the traditional controller based on the "Perturb and Observe" algorithm ( $\mathrm{P} \& \mathrm{O}$ ). The system is simulated under Simulink/Matlab environment. The simulation results show that the fuzzy MPPT controller is faster and more stable during abrupt changes in irradiation values.
\end{abstract}

* Corresponding author: hassan.essakhi@edu.uiz.ac.ma 


\section{Introduction}

In order to integrate the renewable energies in the electric grid and minimizing the pollution resulting from the use of fossil fuels and to guarantee a better yield of green electricity production. It is necessary to control the sources of renewable energies such as solar photovoltaic or wind power. In this context we began with photovoltaic energy; nevertheless, the production of this energy is nonlinear and it varies according to the irradiance and the temperature. This paper is organized as follows: paragraph 2 is reserved for the study of the photovoltaic system; the first sub-paragraph is reserved for the presentation of the photovoltaic panel and their mathematical model. After that, we will simulate this model on SIMULINK software. The second subparagraph is reserved for the study of the DC-DC converter. In the third sub-paragraph, we are interested in the MPPT control; which we will simulate two algorithms: one based on the conventional P\&O algorithm and the other based on fuzzy logic. Finally, we will conclude the simulation results of this work

\section{The photovoltaic system}

The photovoltaic system is controlled by the MPPT command; it is presented in Figure 1

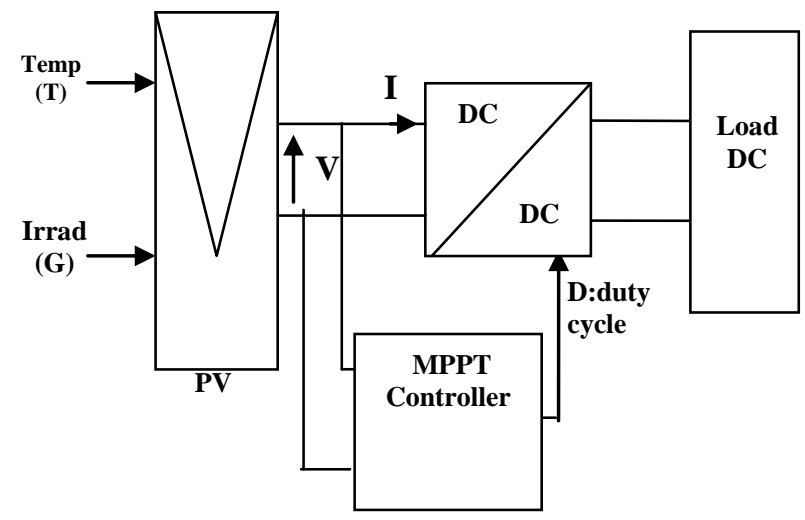

Fig. 1. The photovoltaic system.

A photovoltaic system is divided in four blocks: the first block represents the energy source of the photovoltaic panel whose role is to convert the solar irradiance to direct current, the second block is a DCDC static converter that allows making an impedance matching so that the panel delivers the maximum power, the third block represents the MPPT control system based on an algorithm that allows acting on the duty cycle to continuously extract maximum power, and The fourth block represents the DC load.

\subsection{PV Array Modeling}

A PV module consists of a number of solar cells connected in series and parallel to obtain the desired voltage and current output levels. A solar panel cell is a p-n semiconductor junction. When exposed to the solar irradiance, a DC current is generated. The generated current varies linearly with the solar irradiance. For simplicity, the single-diode model of Figure 2 is used in this paper. This model presents a perfect compromise in terms of simplicity and precision $[1,2]$. The equivalent circuit of the general model which consists of a photocurrent (Iph), a diode, a shunt resistor ( $\mathrm{Rp}$ ) representing a leakage current, and a series resistor (Rs) expressing an internal resistance to the circulation of the current, is shown in Figure 2 [3].

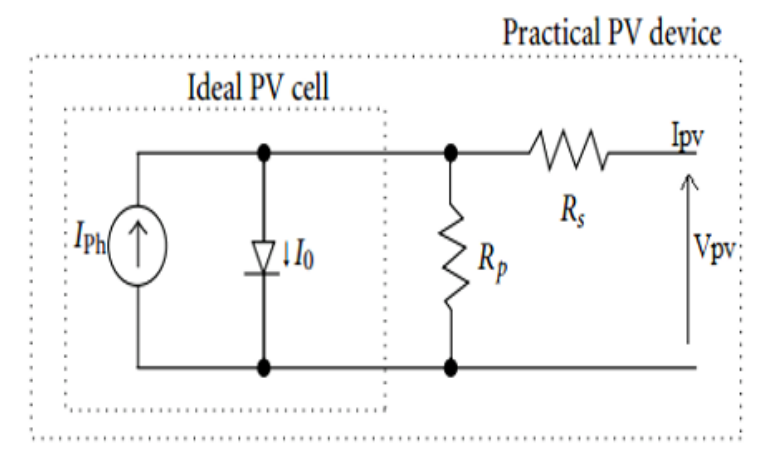

Fig. 2. Equivalent Model of PV cell

In Figure 2 By applying Kirchhoff law, the current will be obtained through this equation:

$$
I p v=I p h-I_{0}-I p
$$

Where: Ipv: PV generator current supplied (A), and Iph is the photocurrent that mainly depends on the solar irradiance and cell's working temperature, which is described in Equation (2) [4]

$$
I p h=\left[I_{s c}+K_{i} \cdot\left(T_{c}-T_{r e f}\right)\right] \cdot \frac{G}{G_{r e f}}
$$

Where Isc is the cell's short-circuit current at a $25^{\circ} \mathrm{C}$ and $\left(1000 \mathrm{~W} / \mathrm{m}^{2}\right), \mathrm{Ki}$ is the cell's short-circuit current temperature coefficient, Tref is the cell's reference temperature in Kelvin $(\mathrm{K})\left(=25 \mathrm{C}^{\circ}+273\right), \mathrm{G}$ is the solar irradiance in $\mathrm{W} / \mathrm{m}^{2}$ and Gref is the cell's reference irradiation $\left(=1000 \mathrm{~W} / \mathrm{m}^{2}\right)$, and $\mathrm{Ip}$ is the current leak in the parallel resistor and is given in this following Equation (3) [4].

$$
I_{p}=\frac{V+I p v \cdot R s}{R p}
$$

$\mathrm{I}_{0}$ : is the diode current (A) which is proportional to the saturation current and is given in Equation (4) [4].

$$
I_{0}=I s \cdot\left[\exp \left(\frac{q \cdot(V p v+I p v \cdot R s}{K \cdot T c \cdot A}-1\right)\right]
$$

Where: Vpv: PV Output voltage (V), $\mathrm{q}$ is the Electron charge $(1.6 \times 10-19 \mathrm{C}), \mathrm{K}$ is the Boltzman constant $(1.38 \times 10-23 \mathrm{~J} / \mathrm{K})$, Tc: is a Cell temperature in Kelvin (K), A is the ideal factor dependent on PV technology, and Rs: is a series resistance $(\Omega)$, and Is is the cell's saturation current varies with the cell temperature, which is described in Equation (5) [4] 


$$
I_{s}=I_{r s} \cdot\left(\frac{T_{c}}{T_{r e f}}\right)^{3} \cdot \exp \left[\frac{q \cdot E_{g}\left(\frac{1}{T_{r e f}}-\frac{1}{T_{C}}\right)}{K \cdot A}\right]
$$

Where Irs is the cell's reverse saturation current at a reference temperature and solar radiation, $\mathrm{Eg}$ : is the bang-gap energy of the semiconductor in the cell in electron-volt $(\mathrm{eV})$.

The Reverse saturation current can be described in Equation (6) [4]

$$
I_{r s}=\frac{I s c}{\exp \left(\frac{q \cdot V_{o c}}{N_{s} \cdot A \cdot K \cdot T_{c}}\right)-1}
$$

Where Isc: is the short-circuit current and Voc: is the open-circuit voltage.

If we replace the equations (3) and (4) in equation (1), the Vpv-Ipv characteristic equation of a solar panel is given as in Equation (7) where $\mathrm{Np}$ is Cell number parallel of the module and Ns is the Cell number in series $(\mathrm{Np}=1$ and $\mathrm{Ns}=36)$ [4].

$I p v=N p \cdot I p h-I s \cdot\left[\exp \left(\frac{q \cdot\left(\frac{V p v}{N s}+\frac{I p v \cdot R s}{N p}\right)}{K \cdot T c \cdot A}-1\right)\right]-\left(\frac{\frac{N p \cdot V p v}{N s}+I p v \cdot R s}{R p}\right)$

\subsection{Simulation of PV panel using Matlab/Simulink}

The used PV Panel for validation of our approach and our algorithms has the specifications summarized in Table 1.

Table 1. The electrical characteristic of the PV panel.

\begin{tabular}{|c|c|c|}
\hline Specifications & Values & $\begin{array}{c}\text { Rating } \\
\text { values }\end{array}$ \\
\hline Pmax & maximum power & $40 \mathrm{~W}$ \\
\hline Voc & open circuit voltage & $21.5 \mathrm{~V}$ \\
\hline Isc & short-circuit current & $2.48 \mathrm{~A}$ \\
\hline Vmpp & maximum output voltage & $16.9 \mathrm{~V}$ \\
\hline Impp & maximum output current & $2.34 \mathrm{~A}$ \\
\hline Tn & Nominal temperature & $25^{\circ} \mathrm{C}$ \\
\hline Gn & Nominal irradiance & $1000 \mathrm{~W} / \mathrm{m}^{2}$ \\
\hline
\end{tabular}

The PV module is implemented under Simulink/Matlab. The model gives the possibility of knowing the behavior of the photovoltaic module for different irradiation values $G$. The curves of Figure 3 and Figure 4 are plotted for three different values of $\mathrm{G}$ with a constant temperature of $25^{\circ} \mathrm{C}: 600 \mathrm{~W} / \mathrm{m}^{2}$, $800 \mathrm{~W} / \mathrm{m}^{2}$, and $1000 \mathrm{~W} / \mathrm{m}^{2}$.

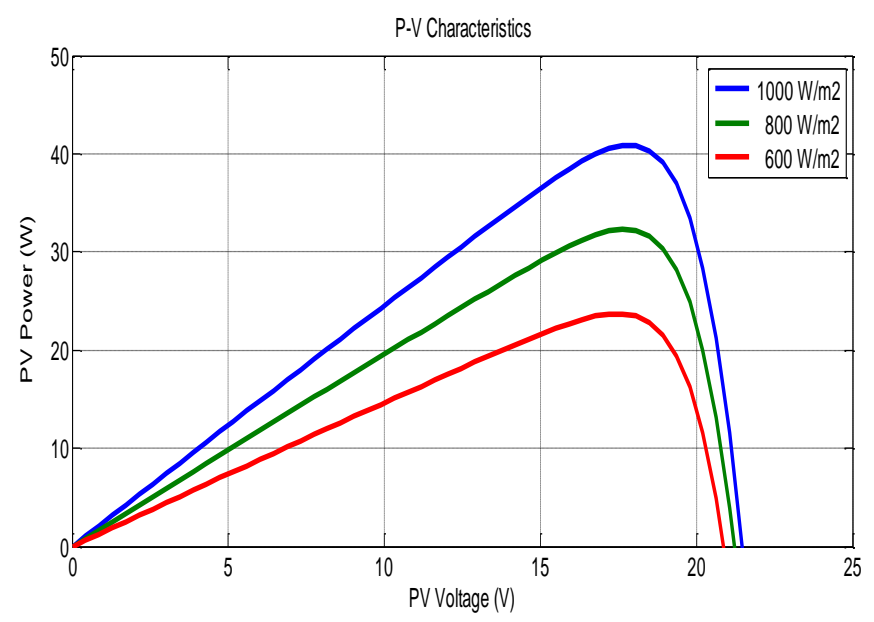

Fig. 3. P-V Characteristics for different Irradiance $\mathrm{G}$ at $\mathrm{Tref}=25^{\circ} \mathrm{C}$

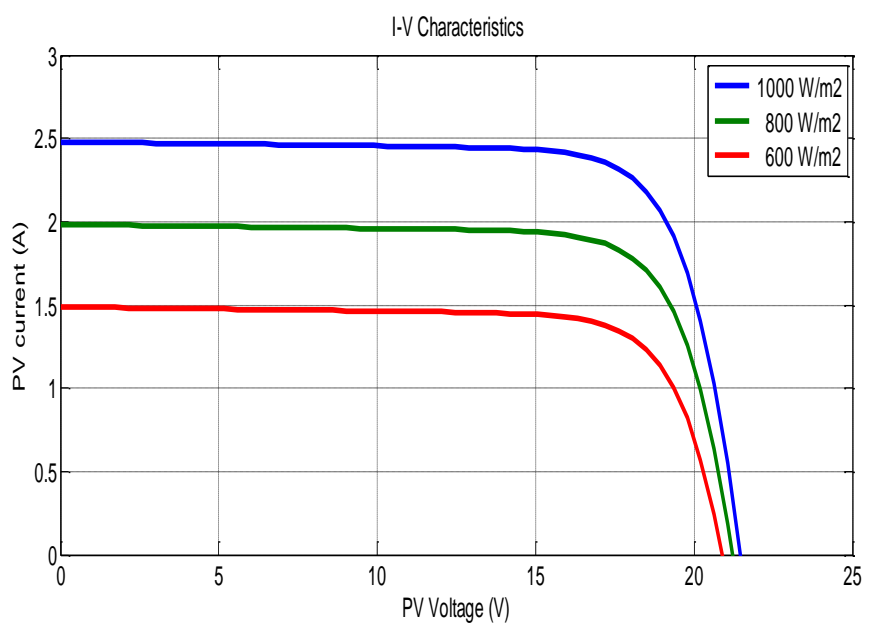

Fig. 4. I-V Characteristics for different Irradiance $\mathrm{G}$ at $\mathrm{Tref}=25^{\circ} \mathrm{C}$

From the previous curves, it can be seen that the current produced by the Iph cell and the power is practically proportional to the solar irradiance $\mathrm{G}$.

The maximum point of the product of $\mathrm{V}$ and $\mathrm{I}$ represent the maximum power point (MPP) Pmax of the solar module, this point corresponds to the MPP whose coordinates are (Vmpp, Impp). The solar panel must always be operated around this point in order to extract the maximum power and to achieve this objective various MPPT algorithms can be used.

\subsection{Boost Converter Modeling}

To get the maximum power, a boost converter is installed between the panel and the charge resistor and we use the duty cycle $\mathrm{D}$ to modify the equivalent charge resistor viewed by the source so that the maximum power is delivered. Consider a boost type converter connected to a $\mathrm{PV}$ module with a resistive load as illustrated in Figure 5.

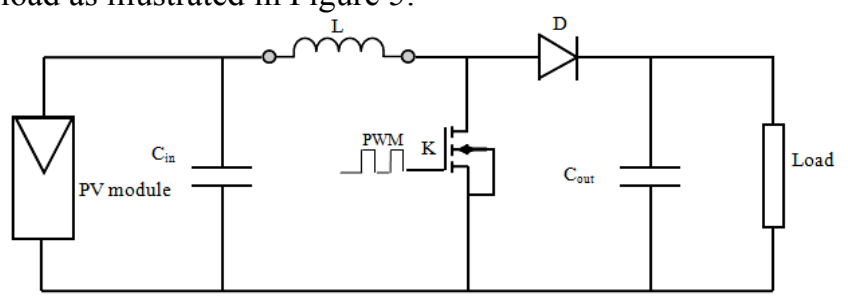

Fig. 5. Boost converter 
Supposing that the inductor current is continuous, the input voltage and output voltage of a boost dc-dc converter at steady state can be expressed in Equation (8):

$$
V_{\text {OUT }}=\frac{1}{1-D} \cdot V_{P V}
$$

Where Vout is the output voltage, Vpv is the voltage input (PV voltage), and $\mathrm{D}$ : is the duty cycle $\mathrm{D}$.

From equation (8) the PV array output voltage can be expressed in Equation (9):

$$
V_{P V}=(1-D) \cdot V_{\text {out }}
$$

We consider an ideal model, neglecting the switching time of the transistor and the values of the internal resistors of the inductor and capacitor. The design of the boost converter leads to the values summarized in Table 2.

Table 2. The electrical characteristic of the boost converter

\begin{tabular}{|c|c|c|}
\hline Specifications & Values & Rating values \\
\hline Cint & Input capacitor & $6.25 \mu \mathrm{F}$ \\
\hline $\mathrm{L}$ & Inductor & $3.5 \mathrm{mH}$ \\
\hline Cout & Output capacitor & $18.22 \mu \mathrm{F}$ \\
\hline $\mathrm{R}$ & Load Resistor & $64 \Omega$ \\
\hline $\mathrm{f}$ & Switching frequency & $20 \mathrm{KHz}$ \\
\hline
\end{tabular}

\subsection{MPPT algorithm control}

The major challenge of MPPT algorithms is to automatically search the point of coordinates (VMPP, IMPP). This point corresponds to the maximum PMPP power supplied by a photovoltaic panel under a given temperature and irradiance $[5,6]$.

Various MPPT techniques have been recently developed and used, for example, the Constant Voltage Tracking (CVT) technique, the Hill-Climbing technique such as the Perturb and Observe $(\mathrm{P} \& \mathrm{O})$ technique, and the Incremental Conductance Technique (INC). Incremental Resistance Method (INR), the Incremental Resistance Technique (INR), the ShortCircuit Current Method, the Fuzzy Logic Control (FLC), and the Genetic Algorithm (GA) [7, 8]; nevertheless, the perturb and observe $(\mathrm{P} \& \mathrm{O})$ technique is widely used, especially for low-cost implementation. But the use of this algorithm has some disadvantages that we will present in section 3 .

\subsubsection{Perturb and Observe (P\&O):}

The $\mathrm{P} \& \mathrm{O}$ control principle consists in generating a perturbation of the operating point (by increasing or decreasing the voltage $\mathrm{Vpv}$ ) then observe the effect on $\mathrm{PV}$ power (Ppv). If the power increases $(\Delta \mathrm{Ppv}>0)$, we are in the right direction; we continue the perturbation in the same direction .if not $(\Delta \mathrm{Ppv}<0)$, we're moving away from the MPP we reverse the perturbation direction [9] as illustrated in Figure 6 The flowchart for the $\mathrm{P} \& \mathrm{O}$ algorithm is shown in Figure 7 where $\Delta \mathrm{D}$ is the perturbation step size

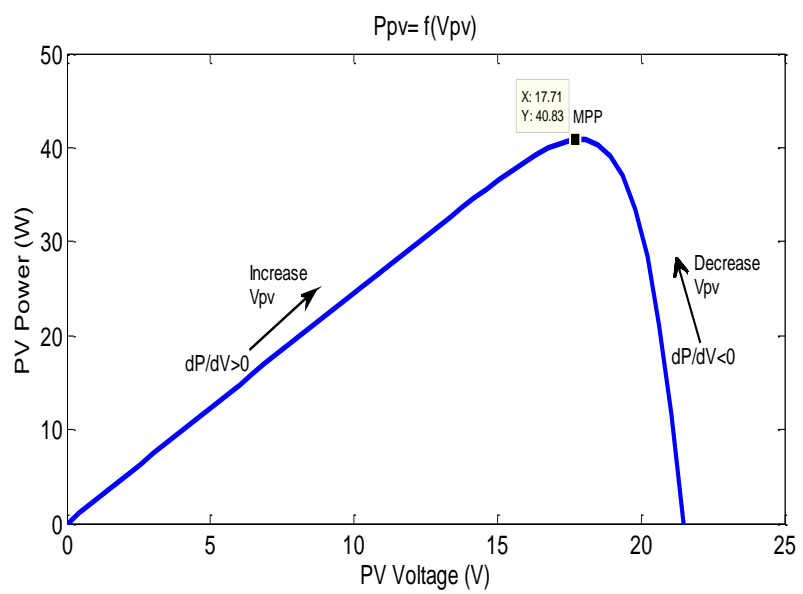

Fig .6. MPPT by P\&O "Hill climbing"

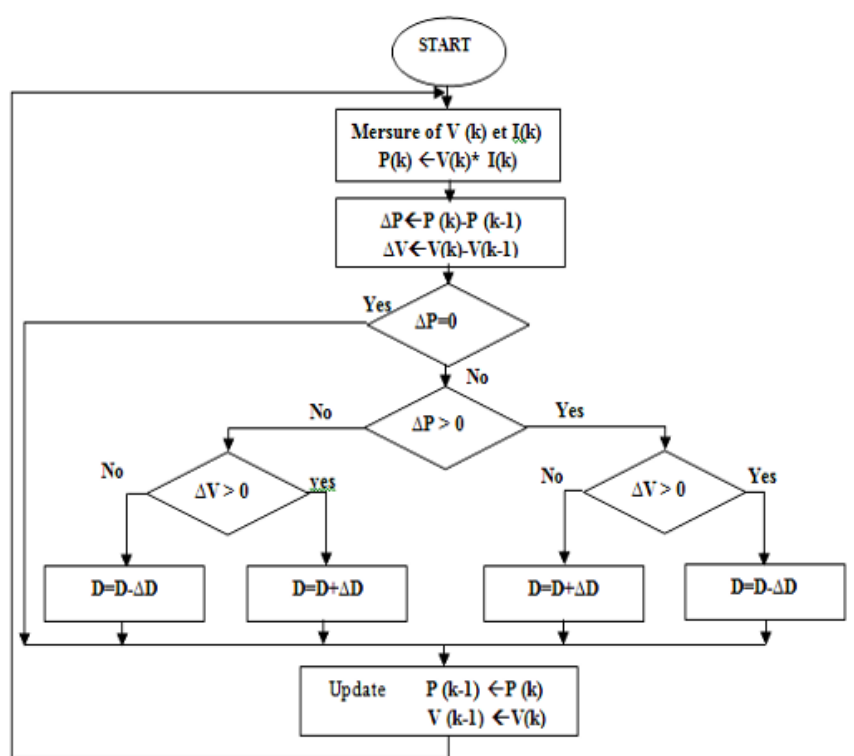

Fig .7. Flowchart of Perturb \& Observe algorithm

\subsubsection{Fuzzy Logic Controller (FLC)}

Fuzzy logic control has been used in MPPT systems; this control offers the advantage of being a robust and fast controller. It does not need exact knowledge of the mathematical model to be regulated [10]. Besides, fuzzy logic simplifies dealing with nonlinearities in systems [11]. The FLC system as shown in Figure 8 has four functional blocks namely: fuzzification, inference mechanism, rule base, and defuzzification $[12,13]$.

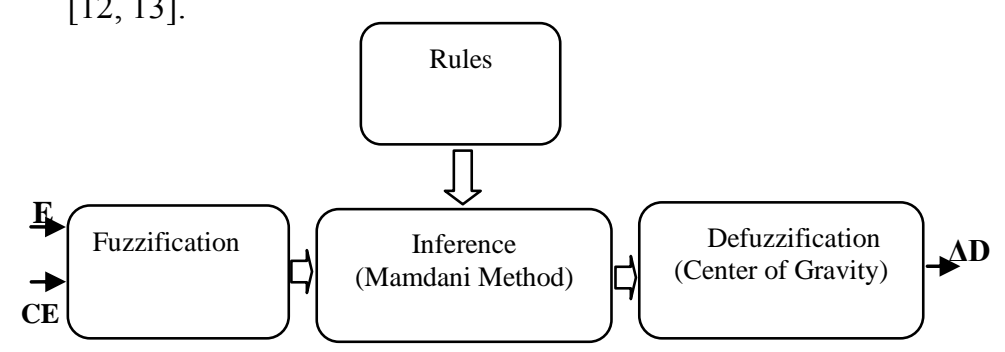

Fig. 8. Block diagram of the fuzzy controller

The proposed fuzzy logic MPPT Controller, shown in Figure 8 , has two inputs and one output. The inputs of 
the fuzzy logic controller will be error $\mathrm{E}(\mathrm{k})$ and Change in Error $\mathrm{CE}(\mathrm{k})$, which are shown in Equation (10) and Equation (11) for sample times k [14].

$$
\begin{gathered}
E(k)=\frac{P_{p v}(k)-P_{p v}(k-1)}{V_{p v}(k)-V_{p v}(k-1)} \\
C E(k)=E(k)-E(k-1)
\end{gathered}
$$

The output $\Delta \mathrm{D}(\mathrm{k})$ allows adjusting the duty cycle that controls the boost converter in order to track the MPP according to climate variations. The duty cycle $\mathrm{D}(\mathrm{k})$ value was calculated using Equation (12) [15].

$$
D(k)=D(k-1)+\Delta D(k)
$$

Input $\mathrm{E}(\mathrm{k})$ shows if the operating point at time $\mathrm{k}$ is placed to the right or to the left of the MPP on the PV characteristic curve, as shown in Figure 6, while input $\mathrm{CE}(\mathrm{k})$ gives the direction of this point. The command action D is the duty cycle of the PWM signal that commands the boost converter.[14,16,17]

Fuzzy processing follows three essential steps:

- Fuzzification:

Fuzzification consists of converting the digital input variables $\mathrm{E}, \mathrm{CE}$, and output variable $\Delta \mathrm{D}$, to linguistic variables and defining the membership functions for the input and output variables.

For this article, five membership functions are used according to the following linguistic variables: Negative Big (NB), Negative Small (NS), Zero (ZE), Positive Small (PS), and Positive Big (PB). Figure $9, \mathrm{a}, \mathrm{b}$ and $\mathrm{c}$, shows the membership functions for the inputs and output of the FLC.

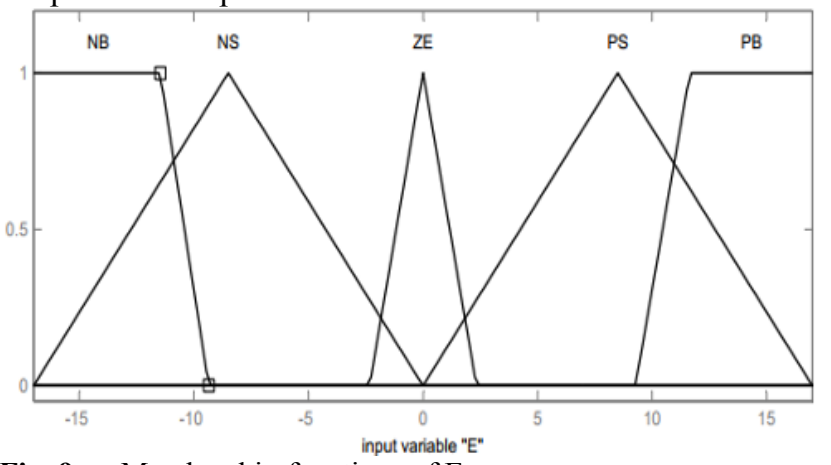

Fig. 9.a . Membership functions of $E$

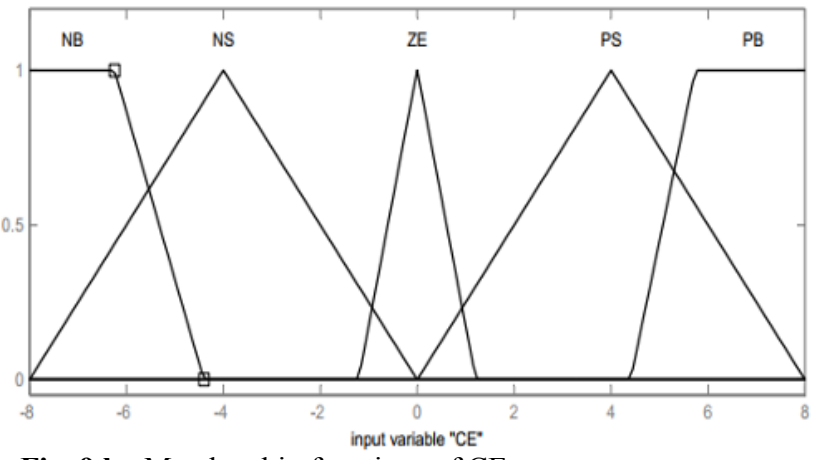

Fig. 9.b . Membership functions of $\mathrm{CE}$

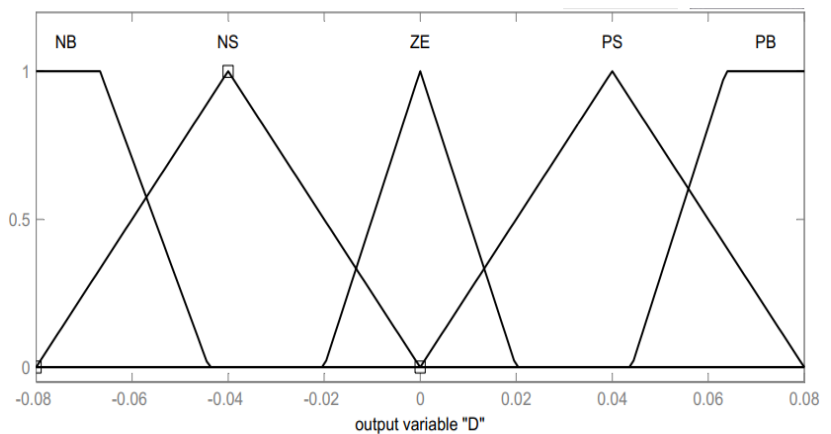

Fig. 9.c . Membership functions of D

- Fuzzy Rules and inference engine

The inference makes the link between an output variable and the input variables transformed into linguistic variables. In our case, the inference is composed of 25 rules listed in Table 3.

Table 3: fuzzy control rules

\begin{tabular}{|c|c|c|c|c|c|c|}
\hline \multicolumn{2}{|c|}{} & \multicolumn{5}{|c|}{ E(k) } \\
\cline { 2 - 7 } \multicolumn{2}{|c|}{} & NB & NS & ZE & PS & PB \\
\hline \multirow{4}{*}{$\mathbf{C E}(\mathbf{k})$} & NB & ZE & PB & PS & ZE & NB \\
\cline { 2 - 7 } & NS & PB & PS & ZE & ZE & NB \\
\cline { 2 - 7 } & ZE & PB & PS & ZE & NS & NB \\
\cline { 2 - 7 } & PS & PB & ZE & ZE & NS & NB \\
\cline { 2 - 7 } & PB & PB & ZE & NS & NB & ZE \\
\hline
\end{tabular}

For this article, the inference method preferred is Mamdani's method, and for the digital processing of inference, we use the Max-min method.

- Defuzzification

In the defuzzification step, the linguistic variables based on the rules of inference are converted to crisp output. The Center of gravity method for defuzzification is used in this paper; the principle consists in determining the center of gravity of the area calculated previously by the inference method used. The crisp value of the control output $\Delta \mathrm{D}$ is computed by Equation $(13)[18,19]$ :

$$
\Delta D=\frac{\sum_{i=1}^{n} \mu\left(\Delta D_{i}\right) . \Delta D_{i}}{\sum_{i=1}^{n} \mu_{i}\left(\Delta D_{i}\right)}
$$

Where $\mu(\Delta \mathrm{Di})$ is the membership value for point $\Delta \mathrm{Di}, \mathrm{n}$ is the number of rules, in our case $\mathrm{n}=25$ rules

Then the terminal duty cycle is obtained by increasing this variation to the previous value of the control duty cycle. (See Equation 12).

\section{Simulation results and discussion}

The PV system is implemented under the SIMULINK/MATLAB environment. we started to simulate the PV system with the MPPT command based on the $\mathrm{P} \& \mathrm{O}$ algorithm, with two fixed steps $\Delta \mathrm{D}=0.001$ and $\Delta \mathrm{D}=0.01$ at $\mathrm{G}=1000 \mathrm{~W} / \mathrm{m}^{2}$ and $\mathrm{T}=25^{\circ} \mathrm{C}$. 
The evolution of the PV panel output power and the dynamic power response of the system are presented in Figure 10 that shows the simulation results of the classical P\&O method

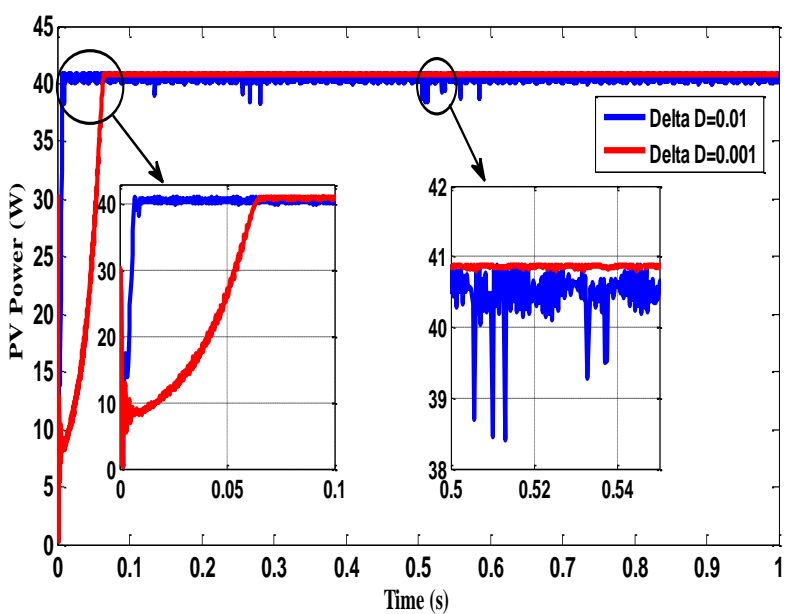

Fig. 10. The response of the $P V$ power using the $P \& O$ algorithm

Figure 10 shows that the MPP is achieved in the steady-state and the MPPT control based on the P\&O algorithm converges to a maximum power point $(\mathrm{Pmpp}=40 \mathrm{~W})$. However, the dynamic response is not the same for the two-step sizes. For $\Delta \mathrm{D}=0.001$ the power response is quite slow $(65 \mathrm{~ms})$ but we notice a small oscillation around MPP.With a higher step size $\Delta \mathrm{D}=0.01$, the response time is reduced $(9.5 \mathrm{~ms})$ but the oscillations around MPP are increased.

Figure 11 shows the response of the Vpv voltage using the $\mathrm{P} \& \mathrm{O}$ algorithm which gives us the order of magnitude of the Vmpp overshoot which equals approximately $18 \%$ of $\mathrm{Vmpp}(\mathrm{Vmpp}=17.8 \mathrm{~V})$ for the two-step sizes, and the value of that overshoot is quite high. We also notice that the overshoot duration for $\Delta \mathrm{D}=0.001$ is longer than the overshoot duration for $\Delta \mathrm{D}=0.01$ and this affects the efficiency of the PV system.

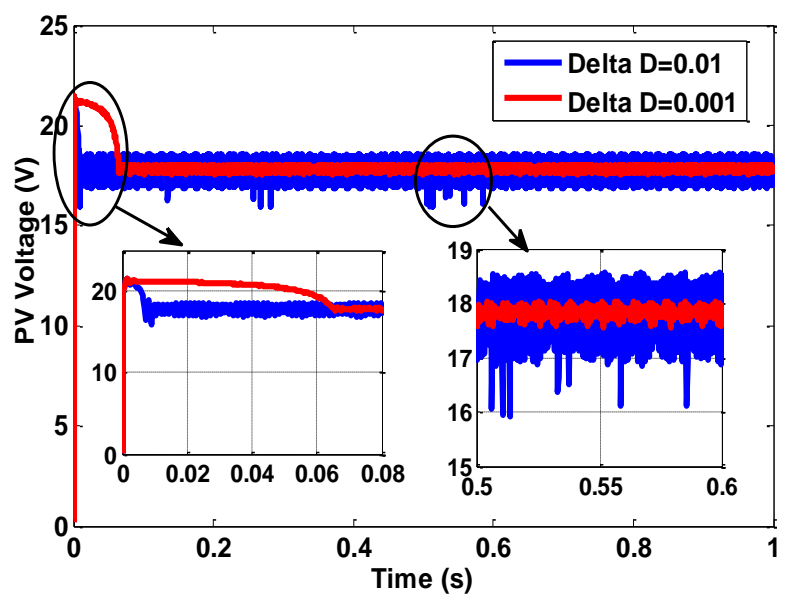

Fig. 11. The response of the Voltage Vpv using $P \& O$ algorithm

So the difficulty in the MPPT based on the P\&O algorithm is the choice of perturbation step size; this step value has a significant influence on the rapidity of tracking the MPP. In fact, better rapidity can be achieved with a large value of this step. But in this case, the operating point will be oscillated significantly around the MPP which results in low system efficiency; this situation is reversed when the value of this step is low.

So, the idea is to have an intelligent MPPT algorithm with variable and flexible step size, that's why we proposed an MPPT controller based on fuzzy logic.

In order to evaluate the dynamic performances of a fuzzy MPPT controller with the conventional P\&O controller, we modeled and simulated the system using SIMULINK/MATLAB software

In the beginning, the PV system is tested at standard test conditions (STC), which are an irradiance of $1000 \mathrm{~W} / \mathrm{m}^{2}$, a cell temperature of $25^{\circ} \mathrm{C}$. The results of the power response by comparing the two MPPT commands FLC and P\&O with fixed step size $\Delta D=0.001$ which are shown in Figure 12 indicate that the proposed FLC compared to classical P\&O is fast to achieve the PPM perfectly, the response time of FLC is assimilated to $3.5 \mathrm{~ms}$. However, for $\mathrm{P} \& \mathrm{O}$ MPPT, the response time equals approximately $65 \mathrm{~ms}$; moreover, the use of the FLC command allows us to have a very stable power response in steady-state as opposed in the $\mathrm{P} \& \mathrm{O}$ control which presents oscillations around PPM

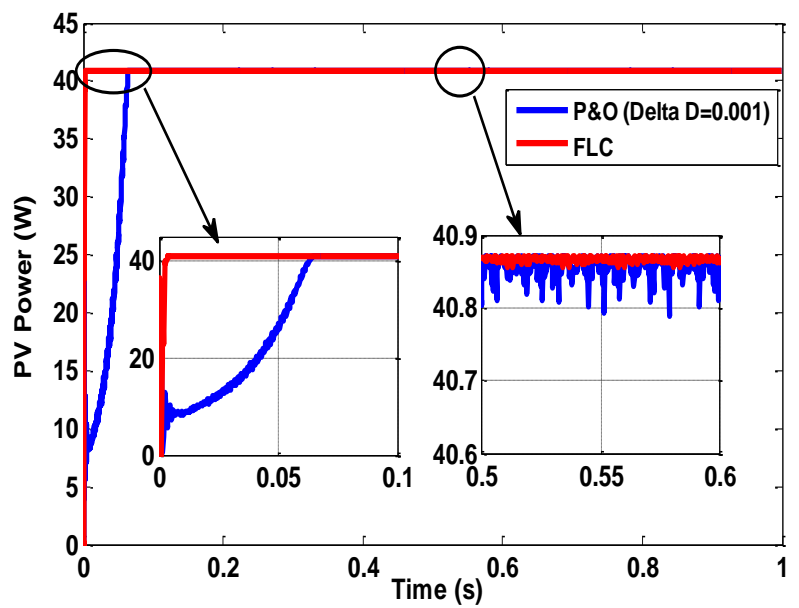

Fig. 12. Output $P V$ power with $P \& O$ and proposed FLC

We can clearly see that the overshoot of the voltage response is a very short peak and practically invisible when using an FLC controller as shown in Figure 13. 


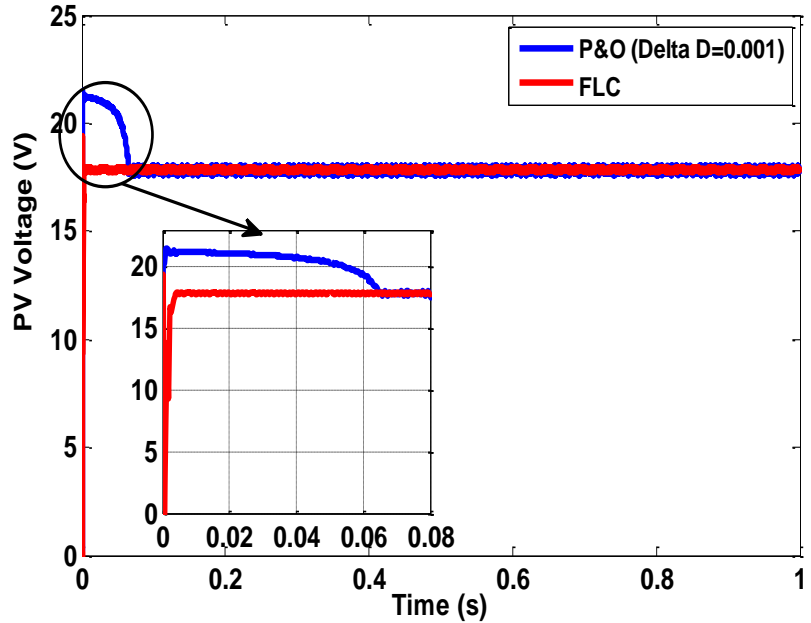

Fig. 13. Output PV Voltage with $P \& O$ and proposed FLC

The next simulation consists in testing the dynamics of the two algorithms according to different irradiance levels at a fixed temperature set at $25^{\circ} \mathrm{C}$. Figure 14 shows the varying levels of irradiance

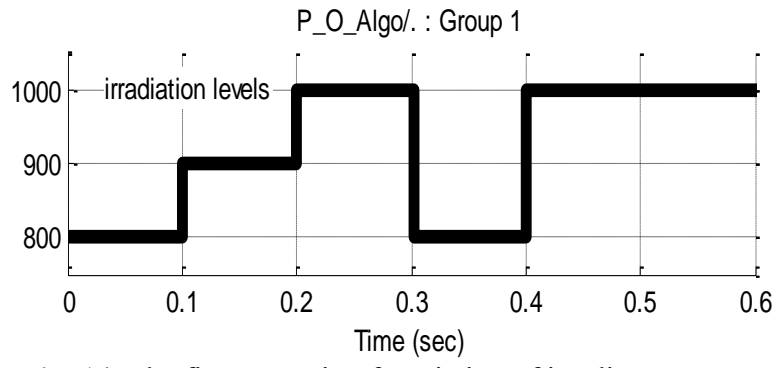

Fig. 14. The first scenario of Variation of irradiance

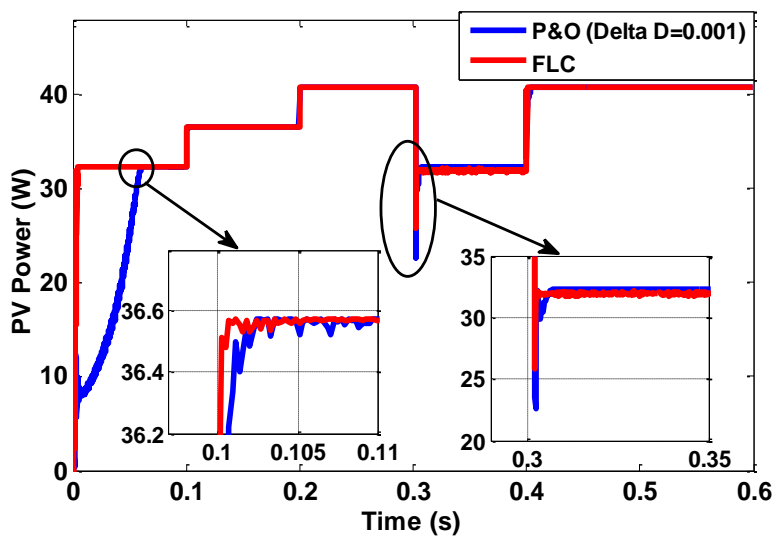

Fig. 15. Output PV power with $P \& O$ and proposed FLC for the first scenario of different irradiance levels

From the data in Figure 15 we notice that the designed FLC has a good starting dynamic to reach the MPP at different irradiance levels. This dynamic is perfectly in alignment with the direction of the MPP. Note also the stability of the power response due to a low oscillation in the permanent regime.

To confirm the dynamic performance of our method we have simulated the second scenario of irradiance levels shown in Figure 16.

Figure 17, Figure 18 and Figure 19 show respectively the response of PV Power; PV Voltage and PV current. The figures display the good behavior of our FLC model to follow different parameters in terms of rapidity and stability such as Pmpp, Vmpp, and Impp, which improves the solar panel performances and PV system efficiency.

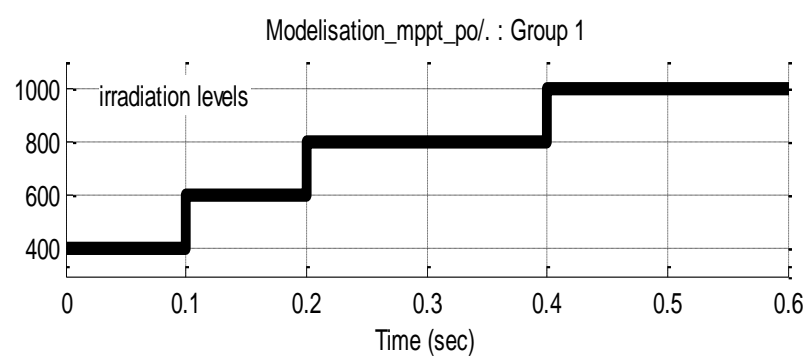

Fig. 16. The second scenario of Variation of irradiance

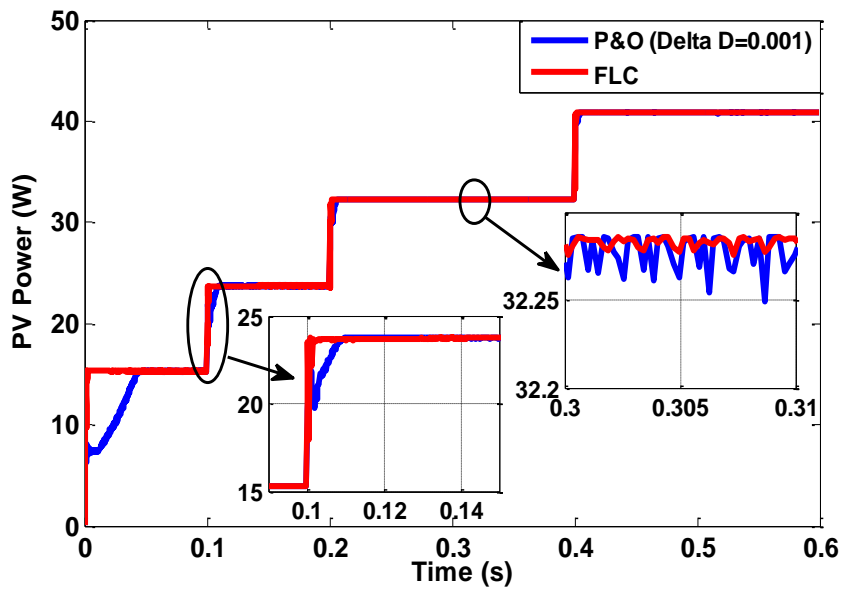

Fig. 17 Output PV power with P\&O and proposed FLC for the second scenario of different irradiance levels

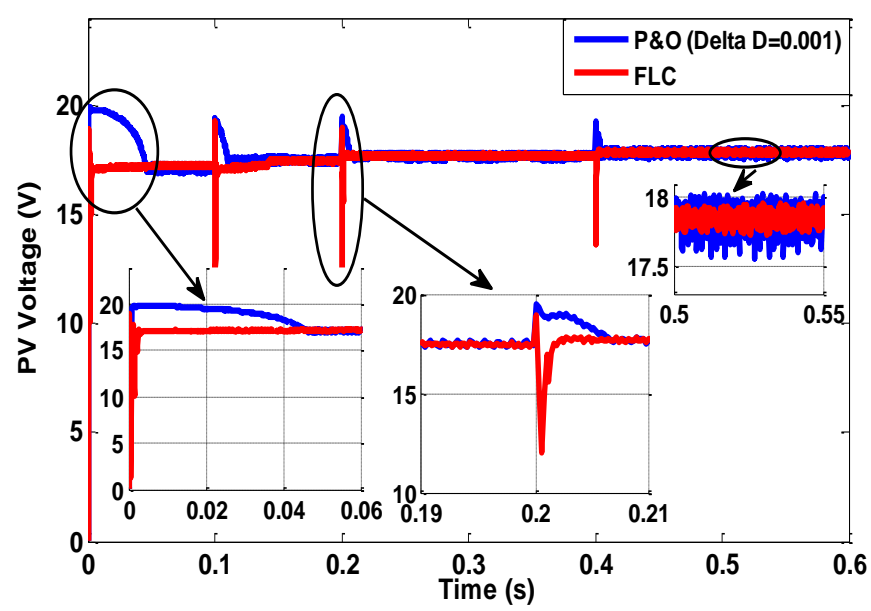

Fig. 18. Output PV Voltage using $P \& O$ and proposed FLC with the second scenario of different irradiance levels 


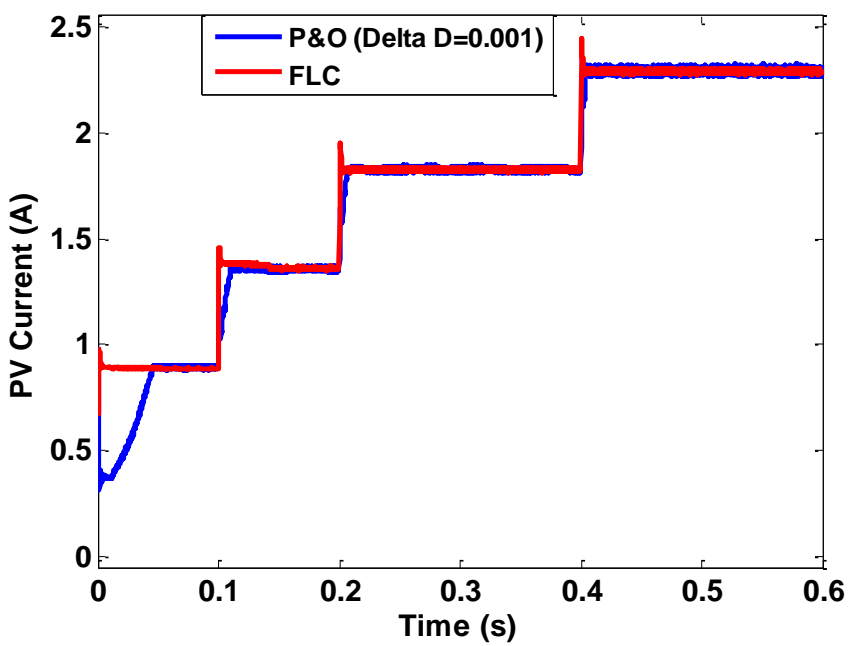

Fig. 19. Output PV Current using P\&O and proposed FLC with the second scenario of different irradiance levels

\section{Conclusion and Perspectives}

This paper has presented complete modeling and simulation of a PV system using SIMULINK (PV module, boost converter, fuzzy and $\mathrm{P} \& \mathrm{O}$ controllers).

We have proposed a Fuzzy logic controller (FLC) and evaluated the performances of the recommended MPPT control under different irradiance levels to track the maximum power point of the PV panel. We have demonstrated that the FLC has high dynamic performances in case of rapid changes in PV operating irradiation. With the proposed method, the response time for tracking the maximum power point MPP is improved from $65 \mathrm{~ms}$ for the classical P\&O algorithm to $3.5 \mathrm{~ms}$ for the proposed fuzzy logic controller. We have demonstrated also that the use of the $\mathrm{P} \& \mathrm{O}$ algorithm makes the maximum point tracking very slow and affects the system stability because it introduces oscillations around the MPP.

So, the main contribution of this article is the guarantee of supplying the maximum possible power with better rapidity and stability by using the proposed method, which improves the efficiency of a PV system.

The next step of this work is to implement this controller on the Arduino board.

\section{References}

1. C. Carrero, J. Amador, and S. Arnaltes, "A single procedure for helping PV designers to select silicon PV modules and evaluate the loss resistances," Renewable Energy, vol. 32, no. 15, pp. 2579-2589, 2007

2. M. G. Villalva, J. R. Gazoli, and E. R. Filho, "Comprehensive approach to modeling and simulation of photovoltaic arrays," IEEE Transactions on Power Electronics, vol. 24, no. 5, pp. 1198-1208, 2009.

3. Natarajan Pandiarajan, RamabadranRamaprabha, and RanganathMuthu., "Application of Circuit Model for Photovoltaic Energy Conversion
System", International Journal of Photo energy Volume, 2012.

4. S. Said, A. Massoud, M. Benammar, S.Ahmed, "A Matlab/Simulink based photovoltaic array model employing SimPowersystems Toolbox," Journal of energy and power engineering, vol. 6, pp. 19651975, 2012

5. Hiren Patel and Vivek Agarwal, "Maximum Power Point Tracking Scheme for PV Systems Operating Under Partially Shaded Conditions", IEEE Transactions on Industrial Electronics, Vol. 55, No. 4, April 2008.

6. Hussein $\mathrm{KH}$, et al. "Maximum photovoltaic power tracking: an algorithm for rapidly changing atmospheric conditions", IEEE Proceedings on Generation, Transmission and Distribution 1995; 142:59-64

7. Trishan Esram, and Patrick L. Chapman, "Comparison of Photovoltaic Array Maximum Power Point Tracking Techniques", IEEE Trans. On Energy Conversion, vol. 22, pp. 439-449, June 2007.

8. D. P. Hohm and M. E. Ropp, "Comparative Study of Maximum Power Point Tracking Algorithms", Progress in Photovoltaics: Research and Applications, vol. 11, pp. 47-62, 2002.

9. N. Femia, G. Petrone, Giovanni Spagnuolo, and M. Vitelli, "Optimization of Perturb and Observe Maximum Power Point Tracking “, IEEE transactions on power electronics, vol. 20, no. 4, July 2005

10. Castro, J.L., "Fuzzy logic controllers are universal approximators"., IEEE transactions on system, man, and cybernetics, Vol. 25, No. 4, 629-635.

11. Wang, L.X., "Stable adaptive fuzzy control of nonlinear systems", IEEE Trans. Fuzzy Systems, 1(2): 146-154. 1993.

12. D. Sushma, N., and Srinivas, "A new fuzzy based improved incremental conductance algorithm for tracking the MPP of a solar PV panel," Int. J. Prof. Eng. Stud., vol. 9, no. 1, pp. 156-163, 2017.

13. Carlos Robles Algarín* ID, John Taborda Giraldo and Omar Rodríguez Álvarez "Fuzzy Logic Based MPPT Controller for a PV System "Energies 2017, 10, 2036

14. M.S.Cheik, Larbes, G.F Kebir and A ZerguelTas; 'Maximum power point tracking using a fuzzy logic control scheme.';'Departement d'Electronique', Revue des Energies Renouvelables, VoI.1O,No 32 , September 2007, pp 387-395

15. Carlos Robles Algarín, 1 *Roberto Liñán Fuentes, 1 and Adalberto Ospino Castro2," Implementation of a cost-effective fuzzy MPPT controller on the Arduino board ", international journal on smart sensing and intelligent systems issue 1 | vol. 11 (2018)

16. G.CD. Sousa, B.K. Bose, "A fuzzy set theorybased control of a phase controlled converter DC 
machine drive", IEEE Trans. Ind. Appl. 30 (I)

(1994) 34-44.

17. N. Drir,L.Barazane and M. Loudini , "Fuzzy logic for tracking maximum power point of photovoltaic generator", Revue des Energies Renouvelables Vol. $16 \mathrm{~N}^{\circ} \mathrm{I}$ (2013) 1 - 9.

18. K.V.Hari Prasad, CH.Uma Maheswar Rao," Design And Simulation Of A Fuzzy Logic Controller For Buck \& Boost Converters", International Journal of Advanced Technology \& Engineering Research (IJATER), Volume 2, Issue 3, May 2012

19. G.CD. Sousa, B.K. Bose, "A fuzzy set theorybased control of a phase controlled converter DC machine drive", IEEE Trans. Ind. Appl. 30 (I) (1994) 34-44 